\title{
Reflexiones sobre la economía mexicana
}

\section{Reflections concerning Mexican economy}

\author{
Sandra Milena Alba Sanabria ${ }^{1}$
}

(.)

Recepción: 03/10/2020
(.)

Aprobación: 04/11/2020
(2)

Publicación: 18/12/2020

Para citar este artículo:

Alba Sanabria, S. M. (2020). Reflexiones sobre la economía mexicana. Indagare, (8), 266-271. https://doi.org/10.35707/indagare/826

\section{(c) $\underset{\mathrm{BY}}{\mathrm{BY}(\mathrm{NC})}$}

${ }^{1}$ Grupo de investigación Zoon Politikon, Universidad de Ibagué, Colombia. Correo electrónico: salbasanabria@gmail.com 


\title{
Resumen
}

El profesor Jerjes Izcoatl Aguirre Ochoa contó, en diálogo virtual, sus principales temas de investigación derivados de las problemáticas económicas que posee México y el estado de Michoacán. Durante sus intervenciones reconoció la existencia de una fuerte situación social producto de la inseguridad que se ha estructurado, al punto de lograr alianzas con las esferas políticas. También expuso cómo se dificultó la relación comercial entre México y Estados Unidos.

\begin{abstract}
Professor Jerjes Izcoatl Aguirre Ochoa expressed, in a virtual dialogue, his main research topics derived from the economic problems that Mexico and the state of Michoacán have. During his speeches, he recognized the existence of a strong social situation as a result of the insecurity that has been settled, to the point of achieving alliances with political spheres. He also discussed how the commercial relationship between Mexico and the United States hampered.
\end{abstract}

Palabras claves: Criminalidad, Michoacán, democracia, gobernanza.

Key words: Crime, Michoacán, democracy, governance.

Figura 1. Retrato de Jerjes Izcoatl Aguirre Ochoa

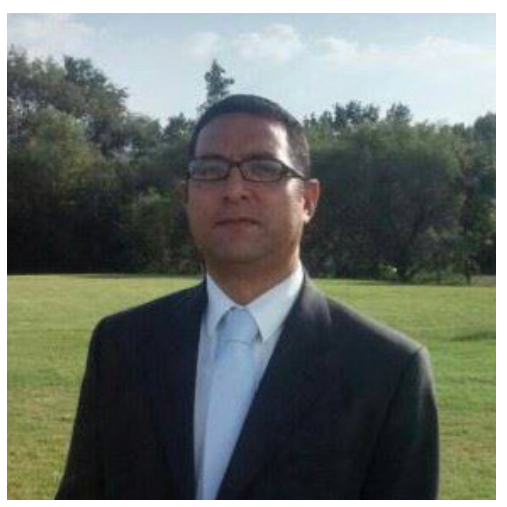

Fuente: Suministrada por el investigador 


\section{Introducción}

El profesor Jerjes Izcoatl Aguirre Ochoa vive en la ciudad de Morelia en el estado de Michoacán de Ocampo en México, es docente de posgrado de la Universidad michoacana de San Nicolás de Hidalgo, hace parte del Sistema Nacional de Investigadores de México y está dedicado a la formación de investigadores y a la producción científica. Recientemente fue invitado por el Programa de Ciencia Política de la Universidad de Ibagué como panelista en el conversatorio Región y pandemia, donde se abordaron los principales conflictos económicos derivados de la pandemia y la forma en que las regiones las han afrontado, a través de una comparación entre las acciones realizadas en Colombia y México.

Luego de este evento, en un diálogo con el profesor Jerjes se profundizó sobre las principales actividades investigativas a las que se dedica y las reflexiones derivadas de estos ejercicios. Desde su mirada económica a la sociedad mexicana, el profesor se interesa por conocer temas de seguridad y crimen organizado, en especial, las afectaciones de orden sociológico que causan estas contrariedades, puesto que su interés es ver los determinantes sociales más profundos de estos procesos criminales.

Ha tenido acercamientos con la Universidad de Ibagué, en específico, con el programa de Paz y Región, que considera interesante y con un enfoque novedoso porque intenta dar una respuesta a los inconvenientes regionales a partir de propuestas de desarrollo y de paz a nivel de localidades. Buscó conocer la experiencia de este programa porque considera que puede ser replicado en México, debido a que existen muchas coincidencias entre las dos sociedades. De la misma manera, con este enfoque regional se podrían crear programas de desarrollo y políticas públicas en zonas con inseguridad y crimen.

De este acercamiento destaca que México coincide con Colombia en muchos aspectos y también en varias complicaciones. Los dos son estados frágiles, democracias incipientes, no se trabaja en la gobernanza de la manera más adecuada, hay ilegitimidad y eso propicia la criminalidad. El Tolima y Michoacán tienen similitudes en su economía, Michoacán también cuenta con una vocación agrícola, fundamentalmente basada en la exportación de aguacate, frutas, minerales y café. Lo anterior hace muy interesante la interacción académica y la vinculación entre las universidades en ambos países.

\section{Criminalidad e interdependencia asimétrica entre México y Estados Unidos}

El profesor Jerjes se encuentra investigando sobre procesos de legitimidad política. Considera que en México está poco estudiado el tema de los gobiernos municipales y la intromisión del crimen en la vida pública se presenta de manera constante en los 
municipios que son los escalones más bajos del Gobierno. Es una figura equiparable a las alcaldías en Colombia, estas esferas poseen mayor cercanía a las personas y allí inicia la intervención criminal.

A partir de la apertura democrática en México se han desarrollado elecciones más competidas con mayor gasto de dinero y se han financiado en buena medida por el crimen organizado. Si un grupo delincuencial apoya un candidato a presidente municipal, desde lo económico o físico, y amenaza a otro candidato, eso puede definir quién gane las elecciones, y una vez electo debe responder a intereses de los grupos que lo apoyaron. Así se empieza toda una cadena de intromisión del crimen con los gobernantes, que no tendría lugar en una nación democrática, porque si así fuese habría los contrapesos para evitar este tipo de nexos entre Gobierno y grupos ilegales.

Para Jerjes esta problemática trasciende los partidos políticos, es un tema en que el país debe tomar una estrategia diferente. El Gobierno mexicano tiene mucha expectativa política y no está trabajando en construir una democracia sólida que pueda ser anticriminal. Esto se debe a que aquello que puede detener a los grupos delincuenciales no son los militares, sino los gobiernos democráticos que logren impedir la intromisión en sus ámbitos y más bien consigan regularlo. Además, México siempre va a tener la presencia de grupos criminales mientras en Estados Unidos haya una gran demanda de droga. Este hecho incentiva la presencia de conjuntos informales que se encargan de suplir la demanda y eso lo hacen países como México y Colombia, dado las condiciones geográficas que poseen.

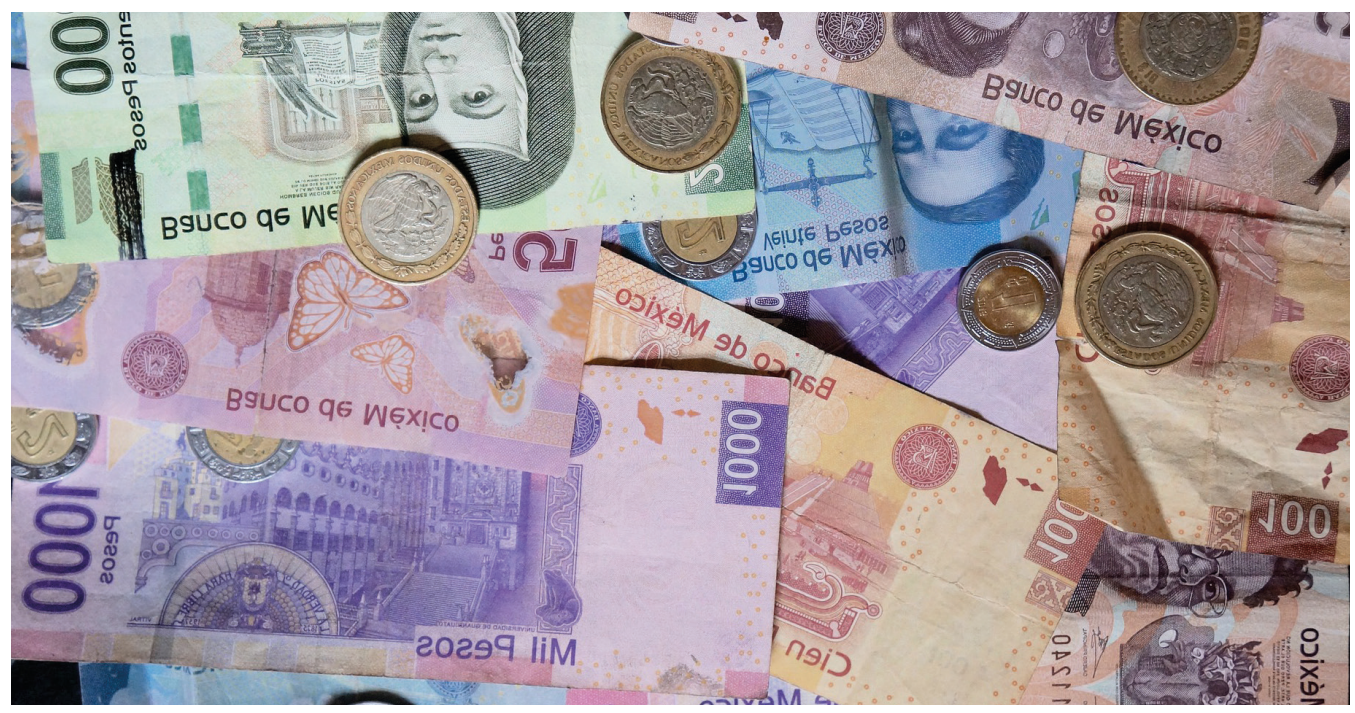


Sobre el tema de la economía mexicana destaca que es más compleja que la economía venezolana o la colombiana en términos de que está muy diversificada. México es un país manufacturero semiindustrial, produce vehículos, refrigeradores, muy parecido a China, pero sin llegar a tener los procesos de diseño tecnológico de los bienes que produce. También hay petróleo, hay minería, hay turismo y llegan remesas provenientes de Estados Unidos producto de la proximidad entre ambos países.

Esta cercanía ha generado una relación de interdependencia asimétrica entre ambos países en términos ambientales por el agua; en condiciones de comercio porque México es el principal socio comercial de Estados Unidos y en asuntos de seguridad. En estos temas cada país depende del otro, aunque México es más dependiente, cualquier cosa que pase en un país afecta al otro. El país centroamericano tiene la primera minoría hispana en Estados Unidos, el 60 \% de los latinos son de origen mexicano y sobrepasan a la población afroamericana. En adición, muchos de ellos, en su mayoría pobres, siguen viajando a Norteamérica a pesar del muro construido por el presidente Donald Trump, puesto que por diez mil dólares pueden pasar la frontera de manera ilegal.

A México le benefician las remesas provenientes de Estados Unidos, que es el dinero que los mexicanos que allí residen mandan a sus familias. Este envío se usa para comprar comida, arreglar casas, costear escuelas y pagar salud. Por lo general, es un recurso que envían, en gran parte hombres, a sus parejas o madres para suplir necesidades básicas. En 2019 ingresaron a dicho territorio 39000 millones de dólares por remesas, es una cantidad muy grande que ayuda a sostener los medios de consumo de muchos estados como Michoacán y Zacatecas.

De otra parte, Estados Unidos se beneficia de la gente que llega al país como migrante, porque esa población cumple roles muy importantes en la economía de dicho territorio. El mexicano que se radica en California va a cultivar la tierra, a cuidar a los ancianos o jardines, incluso, a trabajar en construcción, entonces Estados Unidos ocupa su mano de obra para poder mantener la productividad de muchos sectores de su economía. La dificultad está en que mucha gente se va ilegal y genera procesos complejos y desordenados, dado que no hay control de los dos gobiernos, ni Estados Unidos a los flujos migratorios, ni México de quien está saliendo del país.

En cuanto a lo económico, también se favorecen las compañías estadounidenses de coches que van a México a fabricar autos, debido a que los pueden vender más económicos en Estados Unidos respecto a su competencia con Japón o Corea, porque fueron construidos con costos laborales más bajos. Si México no existiera tendrían que hacer los coches en Estados Unidos y pagar el salario a 20 o 30 dólares la hora lo cual les quitaría competitividad. 
Para finalizar, el profesor Jerjes afirma que mejorar la economía y redireccionar el rumbo social pasa necesariamente por construir una democracia más funcional, una buena ciudadanía y una buena gobernanza, y eso se logra de forma lenta a partir de la educación. Un pueblo educado se da cuenta de que la democracia es una manera imperfecta de gobierno, pero es el mecanismo menos malo para que cada ciudadano tenga voz y voto. También adquiere conocimiento sobre los contrapesos legales que debe tener un gobierno para una buena democracia, que es la interdependencia de las instituciones, un sistema judicial limpio y eficiente, así como gobernantes que sean en realidad representativos de la gente. 